\title{
General Discussion of Dr Brindley et al.'s Paper
}

Chairman: Professor V. PAesLaCK.

SIR Ludwig GutTMAn (G.B.). I am very glad, Dr Brindley, that you stressed from the beginning that this procedure is in a very early experimental stage. There is no question from what you have shown that the people walk much better in their calipers using their trunk muscles to move the pelvis as this has been established by our previous research, but I am surprised that your patient with a TI2 lesion still walks with a walkingto-gait and not with a swinging-through gait which most paraplegics at that level are able to do. TI2 lesion can walk very well and quite quickly in their calipers. In comparison with what you showed us here with your implantation I think that, for the time being, is pretty poor and you yourself mentioned the difficulties that suddenly one leg goes in front of the other and on stopping he slumps down into his wheelchair. I think there is a very long way to go on this but it will be interesting to see the whole thing in a year's time, not only with regard to improved walking but also whether the implantation has come out or not.

DR G. S. BRINDLEY (G.B.). Can I just answer the point about the swinging through. It happened that when we, at the time of the video taping he was walking as you saw, but this man does in fact swing through with his implant also. I am sorry we did the video taping in a small room and he only does the swinging through when he has a big room.

SIR Ludwig GutTMan. I take it you saw yourself of course the much greater deformity of the spine caused by the different type of walking after the implantation. Did you notice that?

DR G. S. BRINDLEY. No I must say I didn't. Thank you.

DR F. W. MeINecke (Germany). Professor Brindley, sorry I do feel first of all I should apologise to ask this question now. As a surgeon I am a little in doubt whether the risk inherent in this implantation is really in accordance with the possible advantages those patients are getting. We saw a slide from you with eight receivers inside and if I remember that other people are implanting receivers for the bladder and other ones are implanting receivers for pain relief, I do fear there will come a time that the patients have inside probably about 12 receivers. I do feel there are many risks and Sir Ludwig just mentioned this possibility when he asked you to tell us what happened with the receivers. I am in doubt that this method is really suitable to the patients.

DR G. S. BRINDLEY. I think I am not really worried about the receiver blocks at all. I think the experience of $\mathrm{Mr}$ Abrams in Birmingham with induction linked pacemakers going over 16 years or even more than that now, shows that they can stay in and function for a very, very long time. That is in his case of course single receivers. It happens that we are using blocks of six in these patients. We have had an epileptic patient with a cerebellar stimulator with a block of eight receivers going for 3 years. In fact multiple receivers are going to be supplanted very shortly by an implanted multiplexing system whereby we could stimulate up to 32 nerves from just two radio channels, and the implanted system required to do that is actually smaller than a block of six receivers such as these patients have.

Professor M. WeIss (Poland). I just participated at the meeting in Basle on stimulation of upper extremities. In my own Institute we have already 2 year's experience with upper extremities tetraplegic electronic devices. We do believe that this is a future, because now we have at our disposal different machines and electronics than we had before, particularly with micro-processers and all the different new facilities. A most interesting phenomena we observed after stimulation was none of these stimulators asked for removal. We had not one case for rejection, and observing biological reactions on the stimulation we did not find any pathological things had placed when after two years in two cases were removed experimentally only. The most interesting is that in upper extremities in tetraplegics you can get a facilitation that means that you need 
after some training not so much current to get the same power grip result. We do believe that tetraplegics' future is in electronic implantation devices. I would like to ask what kind of electrode do you use, because we have tried to use carbon fibrous material because it seems to us that it is surely the best material for the moment for long-term application because one of the major problems is surely the tolerance of electrodes for long-term stimulation, and do you put the electrodes into the nerve or around the nerve?

DR G. S. BRINDLEY. The electrodes are outside the nerve. They are mounted in a silicone rubber cuff which fits the nerve very loosely and the electrodes themselves are of 90 per cent platinum Io per cent iridium. I have a specimen, by the way, if anybody wants to see the electrodes and also the receiver array.

Prof: V. Paeslack. Any other questions. Some more Sir Ludwig?

Sir Ludwig Guttmann. Last question. What happened to the fellow after he walked 50 yards as you said, did he collapse?

DR G. S. BRINDLEY. I wonder whether I can imitate it, I'll try. May I borrow a pair of crutches? [Dr Brindley gave a demonstration.]

SiR Ludwig Guttmann. This was not a convincing demonstration. How does the patient sit down?

DR BRINDLEY. That was his demonstration technique, he does this repeatedly, he throws himself into the chair.

Prof. Paeslack. Thank you Dr Brindley for your interesting report. I think we have had a very interesting and good morning. We must finish now.

\section{OBITUARY}

\section{Jelle Jan Miedema}

One of the founders of rehabilitation medicine in Holland died on II June 1978 at the age of $8 \mathrm{I}$.

After he had qualified at Groningen University he went to Java. During the war he was interned there in a Japanese concentration camp and he did not return to the Dutch East Indies again.

He became interested in rehabilitation medicine in a broad field and was the first medical director of the Rehabilitation Centre 'De Hoogstraat', well known for their experience in spinal cord injury patients. In that function he often attended the meetings at Stoke Mandeville and became a member of the Council.

Miedema was the old Dutchman with much experience, a good sense of humour and a wonderful approach to handicapped people.

G. M. PooL 